\title{
Histochemical muscle fibre characteristics of German Heath lamb meat
}

\author{
Milena Fantová, Martin Ptáček, Klára Michnová, Lenka Nohejlová, Jaromír Ducháček \\ Czech University of Life Sciences Prague, Faculty of Agrobiology, Food and Natural Resources, \\ Department of Animal Husbandry, Prague, Czech Republic
}

Received November 6, 2014

Accepted February 25, 2015

\begin{abstract}
Histochemical characteristics of muscle were evaluated in 12 German Heath lambs (6 males and 6 females). The lambs were slaughtered at the age of 150 days and samples of musculus longissimus lumborum et thoracis and quadriceps femoris were collected and measurements of fibre cross sectional area $\left(\mu \mathrm{m}^{2}\right)$, diameter $\left(\mu \mathrm{m}^{2}\right)$, and perimeter $\left(\mu \mathrm{m}^{2}\right)$ were performed. Subsequently the fibre type distribution (\%) was calculated. The dataset was evaluated using SAS 9.3. Significantly higher $(P<0.05)$ cross sectional area, diameter, and perimeter attributes were observed in females compared to males. Significant differences $(P<0.05$ to 0.01$)$ were observed in fibre type distribution between musculus longissimus lumborum et thoracis and quadriceps femoris muscle. The presented study describes evaluation of morphological formation of skeletal muscle tissue performed on a sheep breed of German origin. The results may be useful for meat scientists or meat industry due to close connection of these characteristics to meat quality.
\end{abstract}

Cross sectional area, fibre type distribution, musculus longissimus lumborum et thoracis, quadriceps femoris muscle

The German Heath is an original coarse-wool German sheep breed. The total number of German Heath reached 300 ewes in 2013, according to the performance recording system in the Czech Republic (Bucek et al. 2014). This sheep breed is characterized by a specific taste of meat that resembles venison and is low in fat. Vertebrate skeletal muscles are made up of bundles of muscle fibres that are peculiar to their morphological characters, contractile and metabolic properties. The muscle fibre is a major determinant factor of muscle mass because it occupies $75-90 \%$ of the total muscle volume (Lee et al. 2010). Myofibres can be defined by cross-sectional area, length attributes or total number of muscle fibres (Lefaucheur 2010). Brooke and Kaiser (1970) described three different skeletal muscle types (I, IIA and IIB fibres) based on differences in myosin ATPase and NADH tetrazolium reductase activity (Suzuki and Tamate 1988) after $\mathrm{pH}$ preincubations. The muscle fibre types are influenced by feed ration (De Marzo et al.2012), body part (Daniel et al. 2007), sex or genotype (Wegner et al. 2000) as previously reported in sheep or other different livestock. Moreover the muscle fibre characteristics have practical importance to meat scientists, breeders, and the meat industry to provide a better understanding of the involvement of muscle fibres with regard to the determination of muscle growth and final meat quality traits such as tenderness, water holding capacity, juiciness or fat content (Hawkins et al. 1985; Čandek-Potokar et al. 1999; Rehfeld et al. 2000; Wegner et al. 2000). As noted by Petracci et al. (2013) higher cross-sectional fibre area is coupled with a significantly higher $(P \leq 0.001)$ incidence of chicken meat abnormalities.

There is practically no information about lamb meat characteristics of German Heath sheep. The population of German Heath sheep has a minority distribution also from the global viewpoint and there are not many studies focused on this rustic sheep breed.

Address for correspondence:

Ing. Martin Ptáček, Ph.D.

Department of Animal Husbandry

Faculty of Agrobiology, Food and Natural Resources

Czech University of Life Sciences Prague

Kamýcká 129, 16521 Prague 6 - Suchdol, Czech Republic

Phone: + 420224383070

E-mail: ptacekm@af.czu.cz

http://actavet.vfu.cz/ 
Therefore the aim of this study was the detailed analysis of German Heath lamb meat with regard to determining the effects of sex and body part on meat properties.

\section{Materials and Methods}

\section{Flock management}

The study was performed on a selected sheep farm in the south border of the Usti nad Labem region. The farm was situated at the altitude of $275 \mathrm{~m}$ above the sea level, with the average annual rainfall of 700 to $800 \mathrm{~mm}$ per year and average annual temperature of $8.0^{\circ} \mathrm{C}$. The animals were kept extensively year-round outdoor using natural shelters only. The feed ration during the grazing season (April to September) consisted of grassland pasture and hay (ad libitum) only. There was no flushing applied before the mating season. In the nongrazing season, the ewes' feed ration consisted entirely of hay (ad libitum). The lamb's feed ration consisted of ewe's milk, grassland pasture, and hay. There was no concentrate supply either for mothers or their lambs. All the animals had permanent ad libitum access to drinking water and mineral licks.

\section{Experimental animals and sampling}

A total of 12 German Heath lambs (males, $n=6$; females, $n=6$ ) were purposely selected from a basic flock of 230 ewes. All the lambs - born and reared singles - came from different mothers at the productive age of 2 to 4 years. The lambs were born from April 1 till April 13 and their birth weight was $2.0 \pm 0.3 \mathrm{~kg}$. They were naturally reared together with the flock. At the age of 150 days the lambs were slaughtered in compliance with the EU laws. Procedures were conducted according to the guidelines of the Council Directive 86/609/EEC on the protection of animals used for experimental and other scientific purposes. After slaughter the carcass weight $(\mathrm{CW})$ was evaluated. At the same time the samples $(5 \times 5 \times 15 \mathrm{~mm})$ of musculus longissimus lumborum et thoracis (MLLT; loin eye area) and quadriceps femoris muscle (QFM; tight area) were collected for subsequent histochemical analyses.

\section{Histochemical analysis}

Samples were frozen in 2-methylbutane cooled by liquid nitrogen $\left(-156{ }^{\circ} \mathrm{C}\right)$ and then stored at $-80{ }^{\circ} \mathrm{C}$ until analysis. Cross-sections $(12 \mu \mathrm{m})$ were cut with a cryostat Leica CM1850 (Leica Microsystems Nussloch GmbH, Nussloch, Germany) at $-20^{\circ} \mathrm{C}$. Subsequently, staining for myofibrillar ATPase was performed after preincubation in alkaline buffer according to methodology by Brooke and Kaiser (1970). The types of muscle fibres were classified as type I (slow-twitch oxidative, slow oxidative, beta red, or red fibres), type IIA (fast-twitch oxidative, fast oxidative glycolytic, alpha red, or intermediate fibres), or as type IIB (fast-twitch glycolytic, fast glycolytic, alpha white, or white fibres) according to the nomenclature of previous authors (Plate I, Fig. 1). Characteristics of muscle fibres (cross sectional area-CSA, diameter, perimeter) were determined using NIS Elements AR software (Version 3.2, Nikon, Tokyo, Japan, 2006). Subsequently the fibre type distribution (FTD; \%) was calculated.

\section{Statistical analysis}

Statistical analysis was carried out using the statistical programme SAS version 9.3 (SAS/STAT ${ }^{\circledR}$ 9.3., SAS Institute Inc., NC, USA, 2011). The correlation coefficients were expressed by using CORR procedure. Detailed evaluation was performed by GLM procedure (ANOVA). The fixed effects in model equation were the sex of lambs ( 2 classes - males and females) and sampling area (2 classes - MLLT muscle fibre and QFM muscle fibre). Regression on the carcass weight was taken into account. Interaction of sex and sampling area was also counted but finally it was excluded from the trial due to its non-significance in the model equation. Tukey-Kramer method was applied for comparison and evaluation the significance of differences between least squares means. Significance levels $P<0.05, P<0.01$, and $P<0.001$ were used to evaluate the differences between groups.

\section{Results}

The correlation coefficients among selected meat attributes are presented in Table 1. The carcass weight was correlated with CSA attributes $(r=0.509$ to $r=0.582)$ or FTD attributes $(r=-0.462$ to $r=0.360)$. Significant correlations $(r=0.802$ to $r=0.989$; $P<0.001)$ were observed among CSA of respective muscle types one another. Significantly positive correlations $(\mathrm{r}=0.427$ to $\mathrm{r}=0.558 ; P<0.05$ to 0.001$)$ were observed among type I muscle fibres in CSA and FTD attributes while negatively correlations among CSA and FTD attributes in both IIA and IIB types were observed $(\mathrm{r}=-0.263 ; P>0.05$ to $\mathrm{r}=-0.506$; $P<0.001)$. Negative correlations $(\mathrm{r}=-0.075 ; P>0.05$ to $\mathrm{r}=-0.850 ; P>0.001)$ were also observed in FTD of all muscle fibre types, mutually.

The basic statistical characteristics of dataset are presented in Table 2. The highest values of CSA $\left(\right.$ mean $\left.=1133.38 \mu \mathrm{m}^{2} ; \mathrm{SD}=374.62 \mu \mathrm{m}^{2}\right)$, diameter $($ mean $=36.49 \mu \mathrm{m}$; 
Table 1. Correlation analysis of selected muscle fibre characteristics.

\begin{tabular}{|c|c|c|c|c|c|c|c|c|}
\hline & & $\mathrm{CSA}$ - total & CSA - I & CSA - IIA & CSA - IIB & FTD - I & FTD - IIA & FTD - IIB \\
\hline \multirow{2}{*}{$\mathrm{CW}$} & $\mathrm{r}$ & 0.539 & 0.582 & 0.509 & 0.520 & 0.360 & 0.097 & -0.462 \\
\hline & $P$ & 0.008 & 0.004 & 0.012 & 0.011 & 0.091 & 0.661 & 0.026 \\
\hline \multirow{2}{*}{ CSA - total } & $\mathrm{r}$ & & 0.849 & 0.973 & 0.989 & 0.558 & -0.506 & -0.326 \\
\hline & $P$ & & $<0.001$ & $<0.001$ & $<0.001$ & 0.006 & 0.014 & 0.127 \\
\hline \multirow{2}{*}{$\mathrm{CSA}-\mathrm{I}$} & $\mathrm{r}$ & & & 0.828 & 0.802 & 0.427 & -0.366 & -0.263 \\
\hline & $P$ & & & $<0.001$ & $<0.001$ & 0.042 & 0.086 & 0.225 \\
\hline \multirow{2}{*}{ CSA - IIA } & $\mathrm{r}$ & & & & 0.956 & 0.512 & -0.489 & -0.286 \\
\hline & $P$ & & & & $<0.001$ & 0.012 & 0.018 & 0.187 \\
\hline \multirow{2}{*}{ CSA - IIB } & $\mathrm{r}$ & & & & & 0.477 & -0.449 & -0.270 \\
\hline & $P$ & & & & & 0.021 & 0.032 & 0.213 \\
\hline \multirow{2}{*}{ FTD - I } & $\mathrm{r}$ & & & & & & -0.641 & -0.850 \\
\hline & $P$ & & & & & & 0.027 & $<0.001$ \\
\hline \multirow{2}{*}{ FTD - IIA } & $\mathrm{r}$ & & & & & & & -0.075 \\
\hline & $P$ & & & & & & & 0.733 \\
\hline
\end{tabular}

CW - carcass weight; CSA - total - cross sectional area of all muscle fibres $\left(\mu \mathrm{m}^{2}\right)$; CSA - I - cross sectional area of type I muscle fibre $\left(\mu \mathrm{m}^{2}\right)$; CSA IIA - cross sectional area of type IIA muscle fibre $\left(\mu \mathrm{m}^{2}\right)$; CSA - IIB - cross sectional area of type IIB muscle fibre $\left(\mu \mathrm{m}^{2}\right)$; FTD - I - fibre type distribution of type I muscle fibre (\%); FTD - IIA - fibre type distribution of type IIA muscle fibre (\%); FTD - IIB - fibre type distribution of type IIB muscle fibre (\%).

Table 2. Basic statistical characteristics of dataset.

\begin{tabular}{lcrrrrr}
\hline Variable & $\mathrm{n}$ & Means & \multicolumn{1}{c}{ SD } & CV & Min & Max \\
\hline CSA - total & 24 & 894.22 & 395.16 & 44.19 & 362.71 & 1868.02 \\
CSA - I & 24 & 1133.38 & 374.62 & 33.05 & 431.39 & 2028.50 \\
CSA - IIA & 24 & 716.44 & 295.00 & 41.18 & 331.29 & 1469.32 \\
CSA - IIB & 24 & 883.56 & 404.55 & 45.79 & 342.79 & 1940.75 \\
Diameter - I & 24 & 36.49 & 6.32 & 17.32 & 21.67 & 49.93 \\
Diameter - IIA & 24 & 28.75 & 5.92 & 20.60 & 19.56 & 42.55 \\
Diameter - IIB & 24 & 31.13 & 6.72 & 21.59 & 19.71 & 46.15 \\
Perimeter - I & 24 & 128.76 & 22.58 & 17.54 & 78.61 & 179.04 \\
Perimeter - IIA & 24 & 110.56 & 40.20 & 36.36 & 68.08 & 236.46 \\
Perimeter - IIB & 24 & 112.81 & 41.73 & 36.99 & 11.55 & 243.34 \\
FTD - I & 24 & 18.35 & 13.29 & 72.43 & 3.24 & 57.32 \\
FTD - IIA & 24 & 20.03 & 7.02 & 35.04 & 3.88 & 31.98 \\
FTD - IIB & 24 & 61.62 & 11.82 & 19.19 & 28.05 & 76.44 \\
\hline
\end{tabular}

$\mathrm{CSA}-$ total $=$ total cross sectional area regardless of muscle fibre type $\left(\mu \mathrm{m}^{2}\right) ; \mathrm{CSA}-\mathrm{I}=$ cross sectional area of type I muscle fibres $\left(\mu \mathrm{m}^{2}\right)$; CSA - IIA = cross sectional area of type IIA muscle fibres $\left(\mu \mathrm{m}^{2}\right)$; CSA - IIB $=$ cross sectional area of type IIB muscle fibres $\left(\mu \mathrm{m}^{2}\right)$; Diameter $-\mathrm{I}=$ diameter of type I muscle fibre $(\mu \mathrm{m})$; Diameter - IIA = diameter of type IIA muscle fibre $(\mu \mathrm{m})$; Diameter - IIB = diameter of type IIB muscle fibre $(\mu \mathrm{m})$; Perimeter $-\mathrm{I}=$ perimeter of type I muscle fibre $(\mu \mathrm{m})$; Perimeter - IIA = perimeter of type IIA muscle fibre $(\mu \mathrm{m})$; Perimeter - IIB = perimeter of type IIB muscle fibre $(\mu \mathrm{m})$; FTD $-\mathrm{I}=$ fibre type distribution of type I muscle fibre (\%); FTD - IIA = fibre type distribution of type IIA muscle fibre (\%); FTD - IIB = fibre type distribution of type IIB muscle fibre (\%); $n=$ number of observation; Min = the lowest value of the muscle fibre histochemical characteristic; Max = the highest value of the muscle fibre histochemical characteristic; Means $=$ average mean of the muscle fibre histochemical characteristic; $\mathrm{SD}=$ standard deviation; $\mathrm{CV}=$ coefficient of variance. 


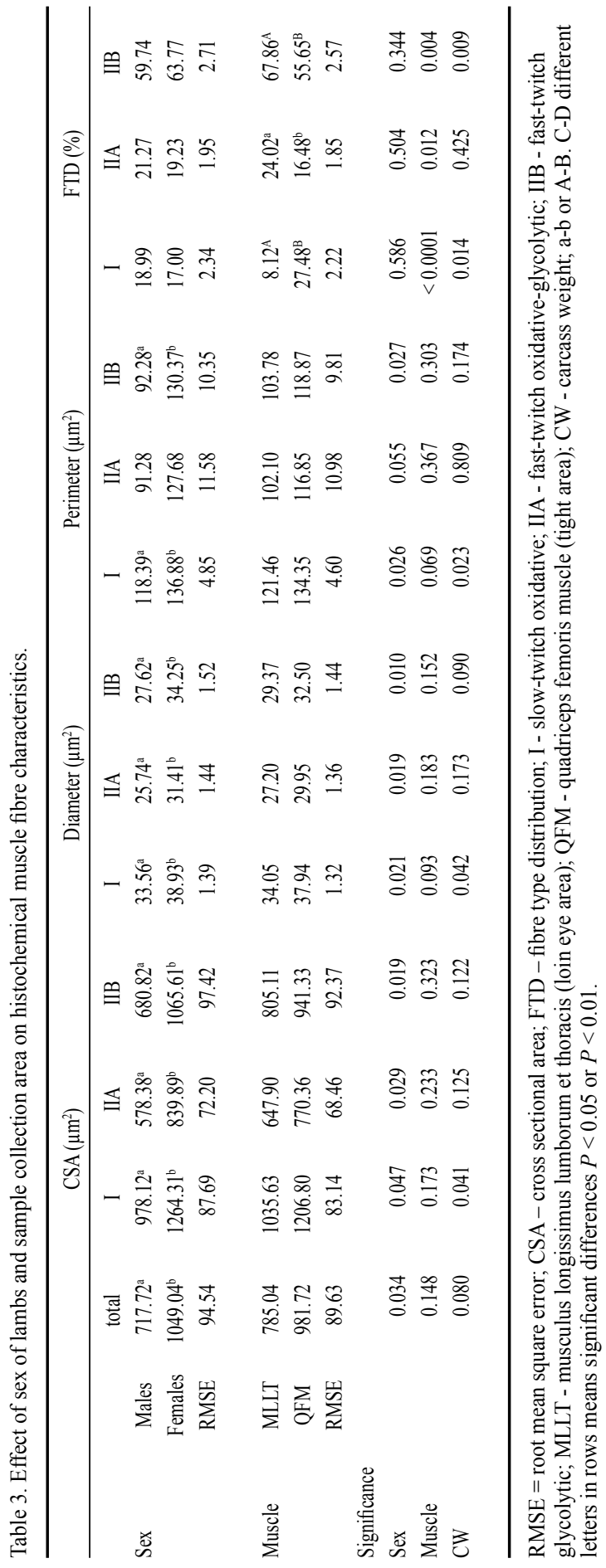

$\mathrm{SD}=6.32 \mu \mathrm{m})$ and perimeter (mean $=128.76 \mu \mathrm{m} ; \mathrm{SD}=22.58$ $\mu \mathrm{m})$ attributes were observed in type I muscle fibres. The highest FTD attribute was marked in type IIB muscle fibres $($ mean $=61.62 \%$; $\mathrm{SD}=$ $11.82 \%$ ). Detailed evaluation of histochemical muscle fibre characteristics performed by ANOVA test is presented in Table 3. Differences in the sex of lambs were observed in CSA, diameter and perimeter attributes. All these attributes were higher in females compared to males $(P<0.05)$. Significantly lower FTD of type I $(-1.99 \% ; P>0.05)$ and type IIA $(-2.04 \% ; P>0.05)$ were observed in females while non-significantly higher FTD of IIB type muscle was observed in females as well. Non-significantly higher values of CSA, diameter and perimeter attributes were marked in QFM compared to MLLT muscle. Significantly higher values of FTD-I resp. FTD-IIA $(+19.36 \% ; P<0.01$, resp. $+7.54 \% ; P<0.05)$ were detected in QFM while the higher FTD-IIB muscle fibre type $(+12.19 \% ; P<0.01)$ was marked in MLLT muscle.

\section{Discussion}

The feed ration influenced the histochemical characteristics of Delle Langhe lambs as previously published by De Marzo et al. (2012). All the lambs evaluated in the study originated from the same flock and were kept under same flock management and breeding conditions; effects of flock, grazing pasture quality or natural conditions were thus eliminated. 
The study of Čandek-Potokar et al. (1999) evaluated relationships of CSA and FTD attributes of the longissimus dorsi muscle fibre. According to their results, FTD both in I and IIA muscle fibres were negatively correlated to FTD in IIB fibres ( $r=$ -0.70 and -0.66 , respectively). These results largely corresponded to ours. Oppositely significant negative correlation between FTD in I and IIA observed in our results indicated that fewer type I fibres were compensated for by an increase of IIA type fibres. The non-significant relationships between CSA and FTD attributes detected in the meat of four different crossbred pigs presented by Borosky et al. (2010) were also observed in our study.

Peinando et al. (2004) described in detail the histochemical indicators of skeletal muscle fibres in Segurena lambs. The value for the diameter of MLLT muscle ranged between 10.45 and $25.20 \mu \mathrm{m}$ in type I fibre; between 5.62 and $13.30 \mu \mathrm{m}$ in IIA and between 6.59 and $21.65 \mu \mathrm{m}$ in IIB type fibres. They noted that type I muscle fibre represented 8.57 to $10.61 \%$; IIA muscle fibre 30.23 to $48.53 \%$ and IIB muscle fibre 41.49 to $60.84 \%$ of distribution of particular fibre types in lambs at the age from one day to 90 days. These results are in partial accordance with ours as detected in German Heath lambs where different figures but similar proportions of fibre type distribution were found. Differences in partial values could be explained mainly by different genotype, age of lambs, feed ration or environment. On the other hand similar proportion of fibre type distribution compared to previous studies confirmed similar physiological development in different breeds of sheep.

As also published by Wojtysiak et al. (2010) the sex of Polish Longwool lambs significantly influenced the diameter of muscle fibres: males had larger diameter of type IIB and IIA fibres than females. Velotto et al. $(2010,2005)$ confirmed the effect of sex on the muscle fibre characteristics of Laticuada or Italian Merino lambs. According to their results males had higher $(P<0.001)$ CSA, perimeter and diameter attributes of muscle fibres compared to females. On the other hand, no effect of the sex of lambs on all the types of FTD muscle fibres in MLLT was noticed in the study published by Wojtysiak et al. (2010). Sex differences on muscle fibre characteristics were affirmed also in other species (e.g. pigs or cattle) by Ozawa et al. (2000), Klont et al. (1998) or Johnston et al. (1981). Our results also confirmed significant differences between males and females in the CSA, perimeter and diameter attributes in the German Heath sheep breed, but in a reversed order. Higher dimension of muscle fibre characteristics in females could be connected with their muscle conformation. As an example, non-significantly higher MLLT depth at the age of 100 days was observed in Texel sheep females compared to males, despite the higher live weight of males (Š tolc et al. 2011).

Differences among muscle fibres were confirmed by Daniel et al. (2007) who evaluated muscle fibre characteristics of different body parts in (Swaledale $\times$ Leicester Blue Face) $\times$ Charollais lambs slaughtered at the age of 24 weeks. They found that the IIB muscle fibres were in a majority and had the largest diameters $(P<0.01)$ in MLLT as well as in the semitendinosus muscle. Differences among muscle fibres between two body parts (m. psoas major - PM - and caput longum $\mathrm{m}$. tricipitis brachii - $\mathrm{ClTb}$ ) in lambs were detected by Velotto et al. $(2005,2003)$. As they presented the CSA, perimeter and diameter dimensions of I, IIA and IIB muscle fibres were higher in ClTb muscle compared to PM at the age of 60 and 120 days. The differences between MLLT and QFM in the German Heath lambs were marked also in our study. On the contrary, Velotto et al. $(2005,2003)$ noted that significant differences $(P<0.05$ to 0.01$)$ were obvious in fibre type distribution attribute only. It is possible to assume that in rustic breeds the muscle fibres of two valuable carcass parts have a similar dimension regardless of the body part but a different distribution of individual muscle fibres.

The quality and sensorial characteristics of meat are influenced mainly by the dimension 
of muscle fibres or by the distribution of IIB in muscle fibres as explained by ČandekPotokar et al. (1999).

From the practical point of view, these muscle fibre attributes are closely connected to qualitative and sensory properties of meat such as fattiness (Hawkins et al. 1985), water holding capacity, tenderness (Rehfeld et al. 2000) or meat juiciness (Čandek-Potokar et al. 1999).

This study presents results obtained in an indigenous German sheep breed ranked among the national genetic resources in Germany. Practically no data about the meat characteristics of this breed were published before. Therefore our results, partially in conformity with the findings of other authors provide new information.

\section{Acknowledgment}

The study was supported by the "S" grant of the Ministry of Education, Youth and Sports of the Czech Republic (MŠMT ČR).

\section{References}

Borosky JC, Rocha MA, Oba A, Pinheiro JW, Bridi AM, Silva CA 2010: Longissimus dorsi miofibre characteristics and meat quality in four pork lines. Arch Zootec 59: 277-286

Brooke MH, Kaiser KK 1970: Muscle fiber types: How many and what kind? Arch Neurol 23: 369-379

Bucek P, Kvapilík J, Kölbl M, Milerski M, Pind'ák A, Mareš V, Konrád R, Roubalová M, Škaryd VM 2014: Annual Report of sheep and goat breeding in the Czech Republic in 2013 (in Czech). Czech-Moravian Breeders Society and Sheep and Goat Breeders Association in Czech Republic, Prague, 85 p.

Council EEC 1986: EEC Council Directive 86/609/EEC of 24 November 1986 on the approximation of laws, regulations and administrative provisions of the Member States regarding the protection of animals used for experimental and other scientific purposes. Off J Eur Union L 358: 1-28

Čandek-Potokar M, Lefaucheur L, Žlender B, Bonneau M 1999: Effect of slaughter weight and/or age on histological characteristics of pig longissimus dorsi muscle as related to meat quality. Meat Sci 52: 195-203

Daniel ZCTR, Brameld JM, Craigon J, Scollan ND, Buttery PJ 2007: Effect of maternal dietary restriction during pregnancy on lamb carcass characteristics and muscle fiber composition. J Anim Sci 85: 1565-1576

De Marzo D, Nicastro F, Toteda F, Nicastro A 2012: Influence of antioxidants to improving meat quality: histochemical characteristics of lamb muscle. Prog Nutr 14: 252-256

Hawkins RR, Moody WG, Kemp JD 1985: Influence of genetic type, slaughter weight and sex on ovine muscle fiber and fatcell development. J Anim Sci 61: 1154-1163

Johnston DM, Moody WG, Boling JA, Bradley NW 1981: Influence of breed type, sex, feeding systems, and muscle bundle size on bovine fiber type characteristics. J Food Sci 46: 1760-1765

Klont RE, Brocks L, Eikelenboom G 1998: Muscle fibre type and meat quality. Meat Sci 49: 219-229

Lee SH, Joo ST, Ryu YC 2010: Skeletal muscle fiber type and myofibrillar proteins in relation to meat quality. Meat Sci 82: 166-170

Lefaucheur L 2010: A second look into fibre typing - Relation to meat quality. Meat Sci 84: 257-270

Ozawa S, Mitsuhashi T, Mitsumoto M, Matsumoto S, Itoh N, Itagaki K, Kohno Y, Dohgo T 2000: The characteristics of muscle fiber types of longissimus thoracis muscle and their influences on the quantity and quality of meat from Japanese Black steers. Meat Sci 54: 65-70

Peinando B, Latorre R, Váquez-Autón JM, Poto A, Ramírez G, López-Alborz O, Moreno F, Gil F 2004 : Histochemical skeletal muscle fibre types in the sheep. Anat Histol Embryol 33: 236-243

Petracci M, Sirri F, Mazzoni M, Meluzzi A 2013: Comparison of breast muscle traits and meat quality characteristics in 2 commercial chicken hybrids. Poult Sci 92: 2438-2447

Rehfeldt C, Fiedler I, Dietl G, Ender K 2000: Myogenesis and postnatal skeletal muscle cell growth as influenced by selection. Livest Prod Sci 66: 177-188

SAS Institute Inc. 2011. SAS/STAT ${ }^{\circledR} 9.3$ User's Guide. Cary, NC: SAS Institute Inc.

Suzuki A, Tamate H 1988: Distribution of myofiber types in the hip and thigh musculature of sheep. Anat Rec 221: 494-502

Štolc L, Ptáček M, Stádník L, Lux M 2011: Effect of selected factors on basic reproduction, growth and carcass traits and meat production in Texel sheep. Acta Univ Agric et Silvic Mendel Brun 59: 247-252

Velotto S, Varricchio E, Di Prisco MR, Stasi T, Crasto A 2010: Effect of age and sex on histomorphometrical characteristics of two muscles of Laticuada lambs. Acta Vet Brno 79: 3-12

Velotto S, Di Prisco MR, Stasi T, Crasto A 2005: Histomorphometrical evaluation of myocyte types in the lambs. Acta Vet Brno 74: 175-182

Velotto S, Guida G, Varricchio E, Gomez de Ayala D, Crasto A 2003: Histoenzymatic localization of myosin 
ATPase (m-ATPase) and succinate dehydrogenase (SDH) in two muscle of the lamb (Gentile di Puglia). Ital J Anat Embryol 108: 175

Wegner J, Albrecht E, Fiedler I, Teuscher F, Papstein HJ, Ender K 2000: Growth- and breed- related changes of muscle fiber characteristics in cattle. J Anim Sci 78: 1485-1496

Wojtysiak D, Kaczor U, Połtowicz K, Krzysztoforski K 2010: The effects of sex and slaughter weight on muscle fibre characteristics and physico-chemical properties of lambs longissimus thoracis muscle. Anim Sci Pap Rep 28: $61-69$ 
Plate I

Fantová M. et al.: Histochemical ... pp. 297-303

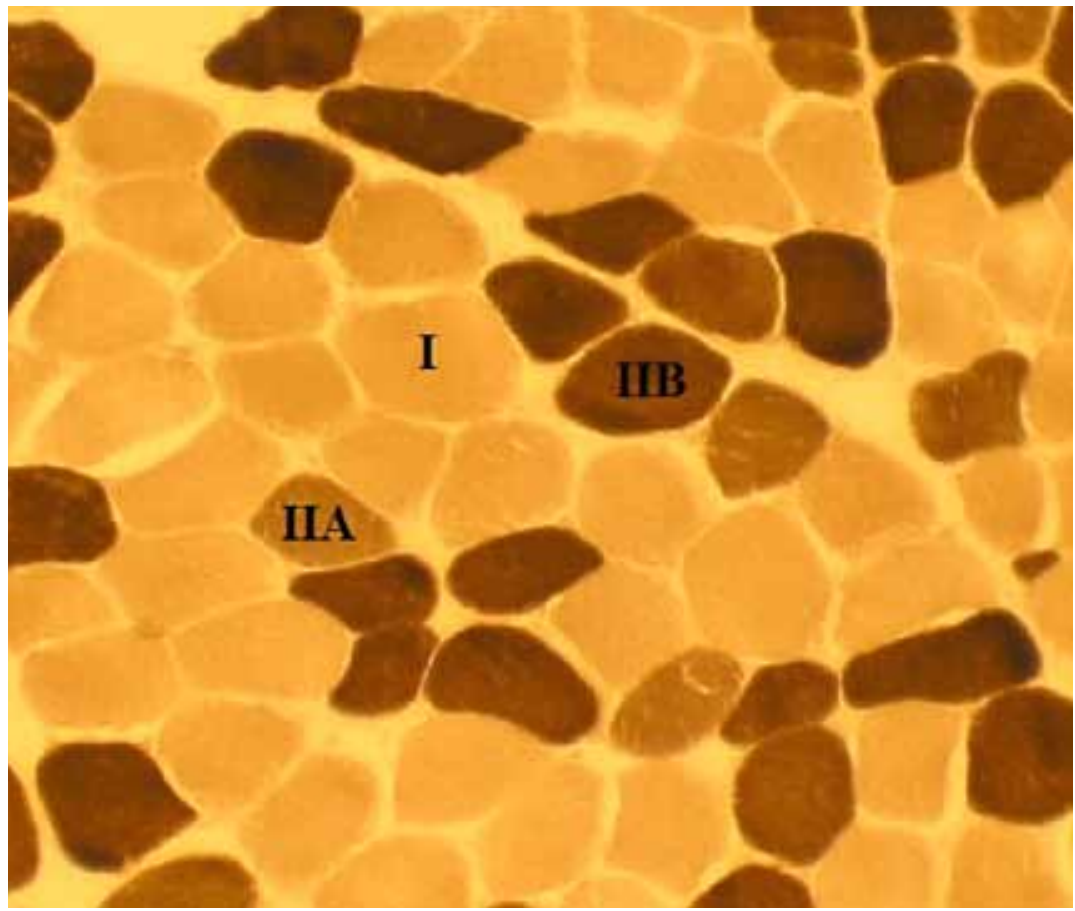

Fig. 1. Muscle tissue fibres after preincubation in alkaline buffer

I - slow-twitch oxidative muscle fibre; IIA - fast-twitch oxidative muscle fibre; IIB - fast-twitch glycolytic muscle fibre (Brooke and Kaiser 1970) 